\title{
Augmentation of bone defect healing using a new biocomposite scaffold: An in vivo study in sheep
}

\author{
U. van der Pol ${ }^{\mathrm{a}, 1}$, L. Mathieu ${ }^{\mathrm{b}, 1}$, S. Zeiter ${ }^{\mathrm{a}}$, P.-E. Bourban ${ }^{\mathrm{b}}$, P.-Y. Zambelli ${ }^{\mathrm{c}}$, S.G. Pearce ${ }^{\mathrm{a}}$, L.P. Bouré ${ }^{\mathrm{a}}$, \\ D.P. Pioletti ${ }^{\mathrm{d}, *}$ \\ a AO Research Institute, Clavadelerstrasse 8, Davos, Switzerland \\ ${ }^{\mathrm{b}}$ Laboratory of Polymer and Composite Technology, Ecole Polytechnique Fédérale de Lausanne, Switzerland \\ ' Département de l'Appareil Locomoteur, University Hospital Lausanne, Switzerland \\ d Laboratory of Biomechanical Orthopedics, Ecole Polytechnique Fédérale de Lausanne, Switzerland
}

\section{A R T I C L E I N F O}

Article history:

Received 29 December 2009

Received in revised form 12 March 2010

Accepted 17 March 2010

Available online 24 March 2010

\section{Keywords:}

Biocomposite

Bone substitute

In vivo

Poly(L-lactic acid)

$\beta$-Tricalcium phosphate

\begin{abstract}
A B S T R A C T
Previous studies support resorbable biocomposites made of poly(L-lactic acid) (PLA) and $\beta$-tricalcium phosphate (TCP) produced by supercritical gas foaming as a suitable scaffold for tissue engineering. The present study was undertaken to demonstrate the biocompatibility and osteoconductive properties of such a scaffold in a large animal cancellous bone model. The biocomposite (PLA/TCP) was compared with a currently used $\beta$-TCP bone substitute (ChronOSTM, Dr. Robert Mathys Foundation), representing a positive control, and empty defects, representing a negative control. Ten defects were created in sheep cancellous bone, three in the distal femur and two in the proximal tibia of each hind limb, with diameters of $5 \mathrm{~mm}$ and depths of $15 \mathrm{~mm}$. New bone in-growth (osteoconductivity) and biocompatibility were evaluated using microcomputed tomography and histology at 2, 4 and 12 months after surgery. The in vivo study was validated by the positive control (good bone formation with ChronOS ${ }^{\mathrm{TM}}$ ) and the negative control (no healing with the empty defect). A major finding of this study was incorporation of the biocomposite in bone after 12 months. Bone in-growth was observed in the biocomposite scaffold, including its central part. Despite initial fibrous tissue formation observed at 2 and 4 months, but not at 12 months, this initial fibrous tissue does not preclude long-term application of the biocomposite, as demonstrated by its osteointegration after 12 months, as well as the absence of chronic or long-term inflammation at this time point.
\end{abstract}

(c) 2010 Acta Materialia Inc. Published by Elsevier Ltd. All rights reserved.

\section{Introduction}

Not all bone losses are similar and correspondingly not every clinical situation needs the same treatment [1]. In particular, when load bearing situations are targeted and the quality of the bone is not optimal for an autograft the surgeon may be tempted to use an artificial scaffold to fill the bone defect. This situation often arises during revision of total knee replacement, where significant bone loss can be found either under the tibial tray or in the femoral part of the knee implant [2]. Unfortunately, in this case the use of calcium phosphate cement is not suitable for filling the bone defects, as this material is too brittle to sustain the shocks that will inevitably arise during normal daily activity [3].

An alternative to a ceramic scaffold could be to use porous bioresorbable polymers such as poly $\alpha$-hydroxyacids [4,5]. However, despite allowing deformation of the scaffold, which is necessary for application in total knee revision, these polymer scaffolds do

\footnotetext{
* Corresponding author. Tel.: +41 2169383 41; fax: +41 216938660

E-mail address: dominique.pioletti@epfl.ch (D.P. Pioletti).

1 These authors contributed equally to this paper.
}

not offer good enough mechanical properties to resist significant loadings. To overcome this mechanical drawback ceramic-polymer composites have gained increasing interest [6-8]. In particular, a biocomposite of controlled porosity combining $\beta$-tricalcium phosphate ( $\beta$-TCP) and poly(L-lactic acid) (PLA) was obtained by supercritical gas foaming [9]. This biocomposite displayed a cellular microstructure and elastic properties close to human trabecular bone [10] and was shown in a numerical study to be able to sustain the load if used as a tibial spacer to fill the bone defect during revision of total knee replacement [11]. In vivo studies in small animals have demonstrated the biocompatibility and osteoconductivity of the biocomposite developed [12]. The results in small animals such as rodents have to be considered with caution if we want to extrapolate them to clinical applications and need, at least, to be confirmed by studies in large animals. The sheep is often chosen as an experimental animal because its bone structure and bone remodelling rate are very similar to those of humans [13].

The aim of this study was to demonstrate the biocompatibility and osteoconductive properties of the new PLA/ $\beta$-TCP biocompos- 
ite in a large animal model over a period of 2, 4 and 12 months and to determine new bone formation, implant degradation and inflammation compared with an untreated (empty) control. A positive control, made of porous $\beta$-TCP, already used clinically as a bone substitute (ChronOS ${ }^{\mathrm{TM}}$ ), was also included in the study.

\section{Materials and methods}

\subsection{Scaffold}

Manufacture of the new PLA/ $\beta$-TCP biocomposite and characterization of its morphology and material properties have been described previously [10]. Briefly, the biocomposite is obtained by a two steps process, namely melt extrusion and supercritical $\mathrm{CO}_{2}$ foaming. PLA granules (Boehringer Ingelheim) and $\beta$-TCP powder (Dr. Robert Mathys Foundation) are first dried to avoid polymer degradation. Both raw materials, in a $95 / 5 \mathrm{wt} . \%$ PLA/ $\beta$-TCP ratio, are mixed and melt extruded in a micro-extrudor (Micro 5 DSM). The composite rods obtained are then cut, dried again, put into a mould and placed in a high pressure and temperature chamber (Autoclave France). The pressure is increased to 225 bar at which pressure PLA melted at $195^{\circ} \mathrm{C}$. Porosity was then created by $\mathrm{CO}_{2}$ release and control of the depressurisation and cooling rates.

The positive control used in this study, ChronOSTM (Dr. Robert Mathys Foundation), is an established bone substitute. ChronOS ${ }^{\mathrm{TM}}$ consists of pure $\beta$-TCP and was obtained using the calcium phosphate emulsion method [14]. Briefly, a hydrophobic liquid is mixed with calcium phosphate paste and an emulsifier. After mechanical stirring an oil/cement paste emulsion is prepared. Once the cement has set and after oil washing porous ceramic blocks are then obtained. Finally, sintering at $1250^{\circ} \mathrm{C}$ leads to porous $\beta$-TCP blocks.

Both types of material, biocomposite and ChronOS ${ }^{\mathrm{TM}}$, were then machined to obtain $15 \mathrm{~mm}$ long by $5 \mathrm{~mm}$ diameter cylinders. All scaffolds were sterilized by $\gamma$-irradiation before implantation.

\subsection{Animal study}

The animal model considered in this study has been described by Zeiter et al. [15]. All animal experiments were performed with the approval of the Veterinary Authority of the Canton Graubünden (no. 16/2006).

Briefly, 13 female Swiss Alpine sheep, with a mean age of 3 years and a mean weight of $50 \mathrm{~kg}$, were used. Two custom made jigs, one with three holes and one with two holes, were used to position the defects in cancellous bone in the femur and tibia, respectively, in a standardized way. Three defects with a diameter of $5.1 \mathrm{~mm}$ were drilled in the distal part of both femora and two in the proximal part of both tibiae (bilateral model), cleaned with saline solution to remove osseous drilling particles and implanted with a scaffold or left empty. In each femur there was a defect filled with the biocomposite (Fig. 1), a defect filled with ChronOS ${ }^{\mathrm{TM}}$ as positive control and one defect left empty as a negative control. In the left tibia one defect was filled with the biocomposite and the other with ChronOS ${ }^{\mathrm{TM}}$. In the right tibia one defect was filled with the biocomposite and one left empty as a negative control. The site of the scaffolds within each bone was evenly distributed between animals to avoid a location bias. Small screws were also inserted in order to correctly position the removal jig at explantation.

Animals were killeded euthanized after 2, 4 and 12 months (4 animals per time point). After positioning of the custom made removal jig with the aid of the positioning screws, implants were harvested using a coring device (trephine attachment, Synthes) with an outer diameter of $12.5 \mathrm{~mm}$. The resulting core consisted of the implant/defect in the centre with approximately $3 \mathrm{~mm}$ of

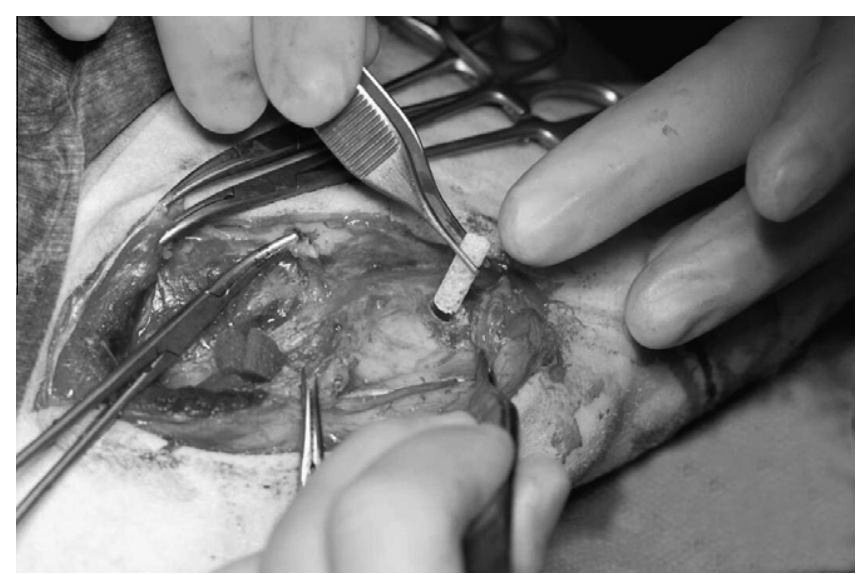

Fig. 1. Medial view of the distal femur. The defects were flushed with lactate Ringer's solution prior to inserting the implants in a drilled defect of $5.1 \mathrm{~mm}$ diameter and $15 \mathrm{~mm}$ depth.

surrounding cancellous bone. Samples were analysed by microCT and histology.

\subsection{Blood analysis}

Blood was taken from each animal before surgery, 1 week and 2 weeks after surgery as well as before being killed euthanized. The total number of white blood cells and the differential blood count were determined.

\subsection{Micro-CT}

The harvested cores were fixed in $70 \%$ ethanol for 3 days prior to micro-CT analysis ( $\mu$ CT 40, Scanco Medical). The long axis of the bone samples was aligned orthogonally to the axis of the Xray beam and a $5 \mathrm{~mm}$ region of interest in the middle of the sample was measured, representing the created defect. In that region bone volume to total volume (BV:TV) was evaluated by thresholding. Additionally three-dimensional (3D) reconstructions of the region of interest were created.

A measurement protocol was created to define the scanning parameters, including a source voltage of $70 \mathrm{kV}$ and intensity $114 \mu \mathrm{A}$. The scans were performed using high resolution settings. Each scan yielded an image data set of 400 slices. The resulting two-dimensional images had an element size of $18 \mu \mathrm{m}$ in all three spatial dimensions. A 3D Gaussian filter with $\sigma=0.8$ and a support of one voxel was used to partially suppress noise.

\subsection{Histology}

Samples were dehydrated in an ascending series of alcohol (50$100 \%$ ) and defatted with xylene. After infiltration of the samples with liquid LR-white in an evacuated container at $4{ }^{\circ} \mathrm{C}$ for 14 days they were polymerized with LR-white into ready to cut sample blocks. A circular saw (Leitz 1600 Saw microtome, Leica) was used to cut $200 \mu \mathrm{m}$ thick cross-sections in the middle of the harvested core.

Macroradiographs (Faxitron X-Ray System, Hewlett Packard) were taken from each cross-section before further preparation of the samples. The sections were then ground and polished down to $80-100 \mu \mathrm{m}$ thick sections (Exact Micro Grinding System, Exakt Apparatebau). Their surface was etched with $1 \%$ formic acid (Fluka) for $30 \mathrm{~s}$, rinsed, stained with $1 \%$ Toluidine blue (Fluka) for $20 \mathrm{~min}$ and blot dried after washing in deionized water. Further, as a sec- 
ond stain Giemsa-eosin was used. Sections were stained in eosin solution for $20 \mathrm{~min}$ and in Giemsa solution for $\sim 3 \mathrm{~min}$.

All stained sections were evaluated qualitatively for new bone formation, implant integration and degradation, as well as signs of inflammation and/or immunological reaction.

\subsection{Histomorphometry}

For quantitative analysis microradiographs were digitized. Relative bone formation within the bone defect was assessed as area of high density (bone) vs. area of low density (soft tissue) by thresholding images using a custom made macro (KS400 v. 3.0, Zeiss) (Fig. 2).

\subsection{Statistics}

All results are given as means \pm standard deviations.

\section{Results}

\subsection{Surgeries}

All surgeries were performed without complications and all samples were introduced into the defects according to the study plan. Animals recovered well from surgery and showed no signs of lameness. One sheep developed pneumonia after 1 month and had to be excluded from the study. This sheep was replaced.

\subsection{Blood analysis}

Total leukocytes counts and the differential blood analysis were within the physiological range for all sheep of all groups during the study.

\subsection{Micro-CT}

The bone volume to total volume ratio (BV:TV) is presented in Fig. 3. In defects treated with the biocomposite BV:TV increased from $1.8 \pm 1.1 \%$ at 2 months, to $3 \pm 1.6 \%$ at 4 months, and to $22.4 \pm 12.3 \%$ at 12 months. In the empty defects after 2 months the BV:TV was $6.1 \pm 3.4 \%$ and healing continued after 4 months, resulting in a BV:TV in the defect area of $13.7 \pm 13 \%$ at 4 months and $16.7 \pm 9.9 \%$ at 12 months. In the defects filled with ChronOS ${ }^{\mathrm{TM}}$ the BV:TV was higher, between 40 and $50 \%$ at all time points. However, the thresholding was difficult to establish with the $\beta$-TCP scaffold as this scaffold responds to micro-CT in the same way as bone hydroxyapatite.

Representative 3D reconstructions of the empty (top) and the biocomposite (bottom) filled defects at 4 months (left) and 12 months (right) are presented in Fig. 4. The treated defect with the biocomposite scaffold showed new bone formation after 4 months at the edges of the defect. The amount of new bone increased with time and the whole volume was filled with newly formed bone with a trabecular structure at 12 months. The empty defect showed dense ring formation from the edge of the defect towards the centre, thickening from 2 to 12 months.
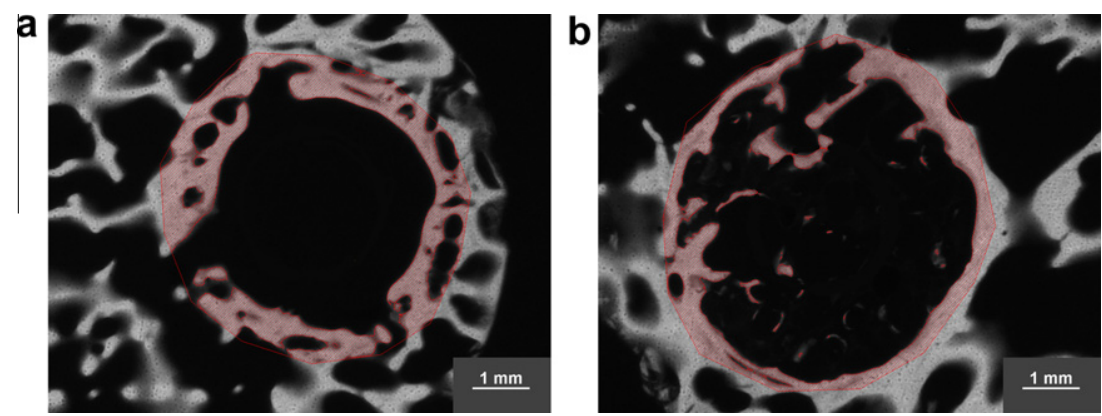

Fig. 2. Microradiographs of two defects (left, empty; right, biocomposite) with different extents of bone in-growth at 12 months.

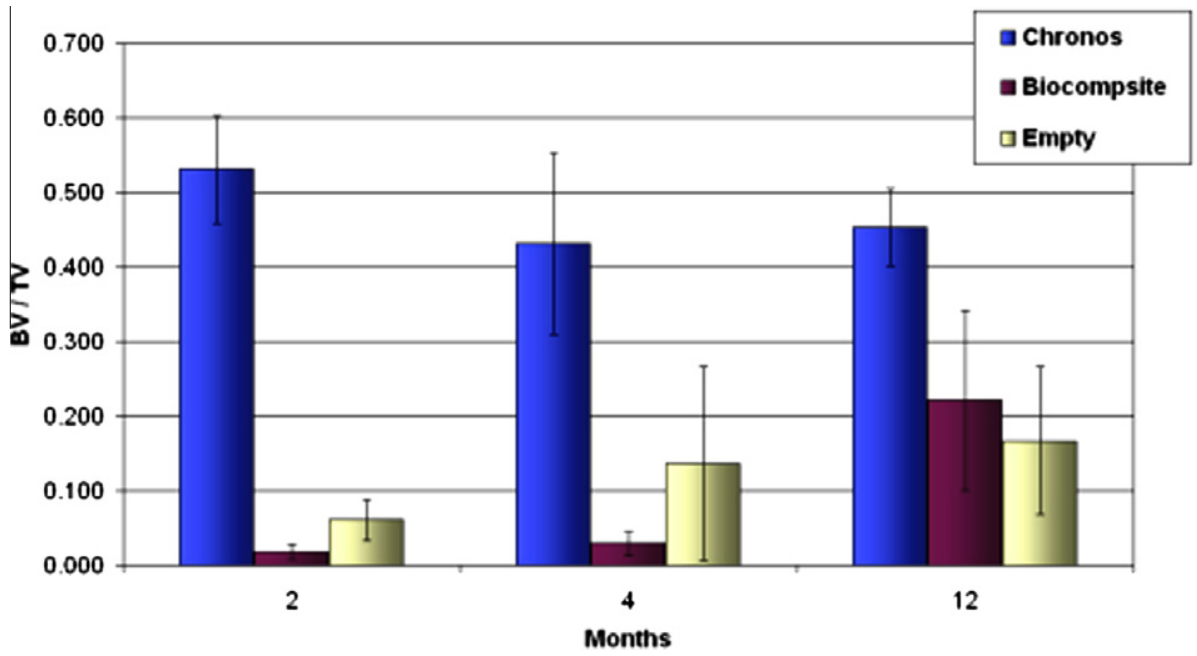

Fig. 3. Micro-CT evaluation. Bone volume to total volume (BV:TV) within the defect area at 2, 4 and 12 months. 

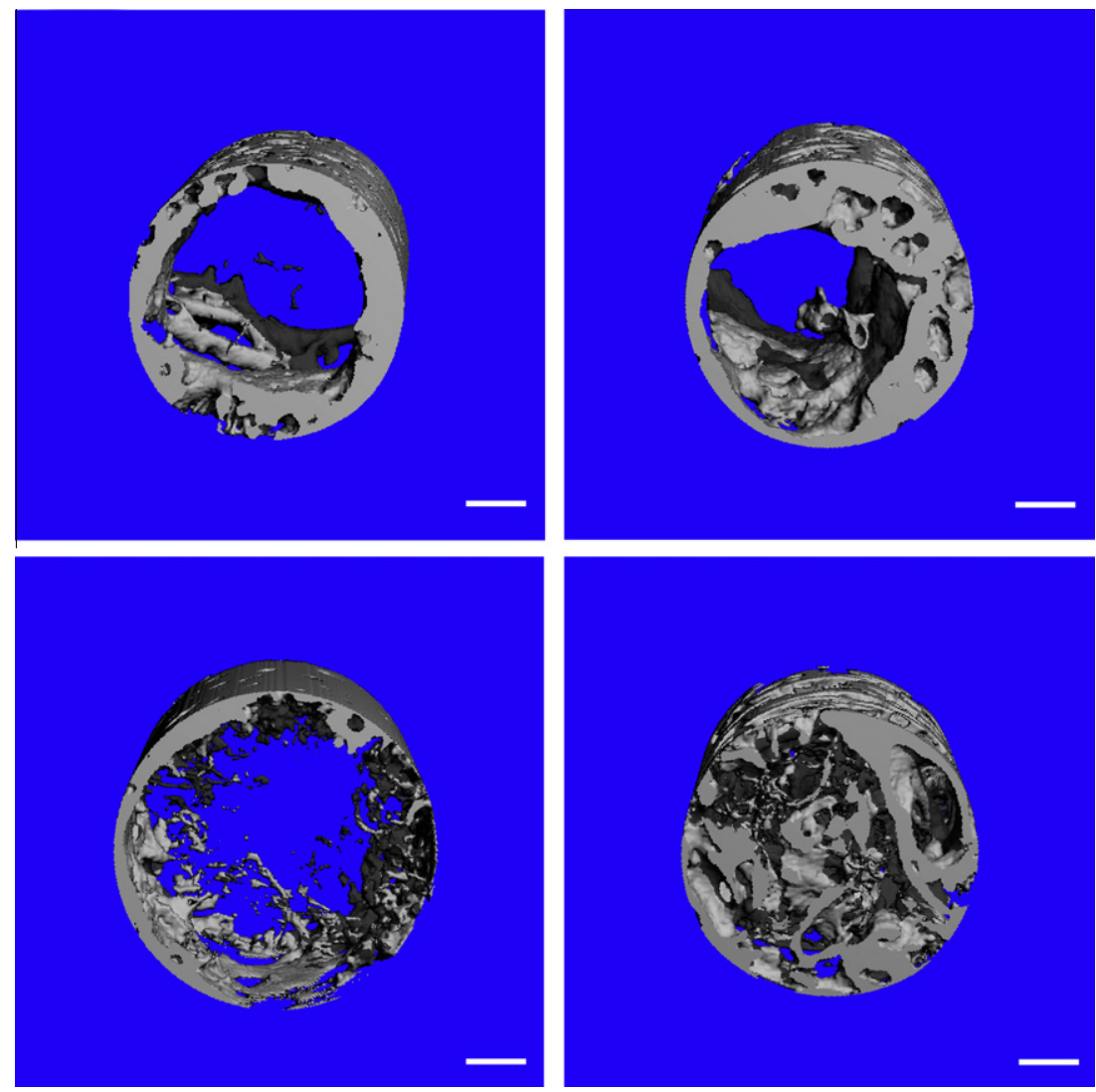

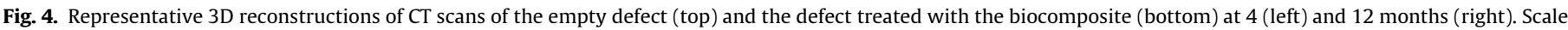
bar $1 \mathrm{~mm}$.

\subsection{Histology and histomorphometry}

New bone formation within the defect area was dependent on the treatment and time point.

\subsubsection{Biocomposite}

At 2 months voids within the biocomposite were filled with an amorphous substance and only a few new bone islands were seen, mainly at the edge of the defect. These bony islands were separated from the biocomposite by a fibrous layer. Around the bone substitute some large foreign body cells and multi-nucleated giant cells were observed. Additionally, a few sporadic inflammatory cells were detected on the outside area of the implant. A bone density of $10.2 \pm 3.7 \%$ was observed in the biocomposite after 2 months. At 4 months new bone formation within the defect had increased slightly to a bone density of $12.6 \pm 3.4 \%$. The fibrous tissue layer between implant material and newly formed bone was still visible. Several accumulations of macrophages and foreign body cells were still visible, with mild and local inflammation signs present. At 12 months the bone density within the biocomposite had increased to $29.4 \pm 4.8 \%$. In all samples new bone was detected in the central region of the biocomposite. In contrast to the 2 and 4 months results, no fibrous tissue encapsulation or inflammatory cells were observed. Although the scaffold material was still visible in the defect area, the amount had decreased remarkably compared with the earlier time points (for representative images see Fig. 5).

\subsubsection{Empty defect}

Remains of haemosiderin and fibrous material were noticed at 2 and 4 months in the centre of the defect. There was a continuing increase in bone density within the defect from $12.9 \pm 2.2 \%$ at 2 months to $26.9 \pm 6.4 \%$ at 4 months. At 12 months $28.4 \pm 15.3 \%$ of the defect was filled with newly formed bone. This bone was formed mainly at the edge of the defect and its structure was denser than the surrounding trabecular bone (for representative images see Fig. 6). No inflammatory cells were observed at any time points.

\subsubsection{ChronOS ${ }^{\mathrm{TM}}$}

Histological analysis revealed good integration of the implant in the bone structure at all time points. The granules of ChronOS ${ }^{\mathrm{TM}}$ were incorporated into newly formed bone. At 2 months granules were still clearly detectable in the centre of the defect. The bone density was at that time point $31.9 \pm 8.0 \%$, which increased to $38.5 \pm 9.8 \%$ at 4 months. By then newly formed bone was noticed even in the centre of the defect area and new trabeculae were formed between adjacent bone and the newly formed bone. Osteoclasts were detected as a sign of ongoing remodelling. Empty trabecular spaces were refilled with non-reactive bone marrow. At 12 months some granules were still visible, but new bone formation prevailed in the defect area. At this time point $40.5 \pm 12.3 \%$ of the defect was filled with bone (for representative images see Fig. 7).

\section{Discussion}

A biocomposite scaffold made of PLA/ $\beta$-TCP was tested in vivo in sheep femur and tibia up to 12 months in a bilateral model. This new bone substitute was compared with a negative control (defect left empty) and a positive control ( $\beta$-TCP scaffold ChronOSTM). 

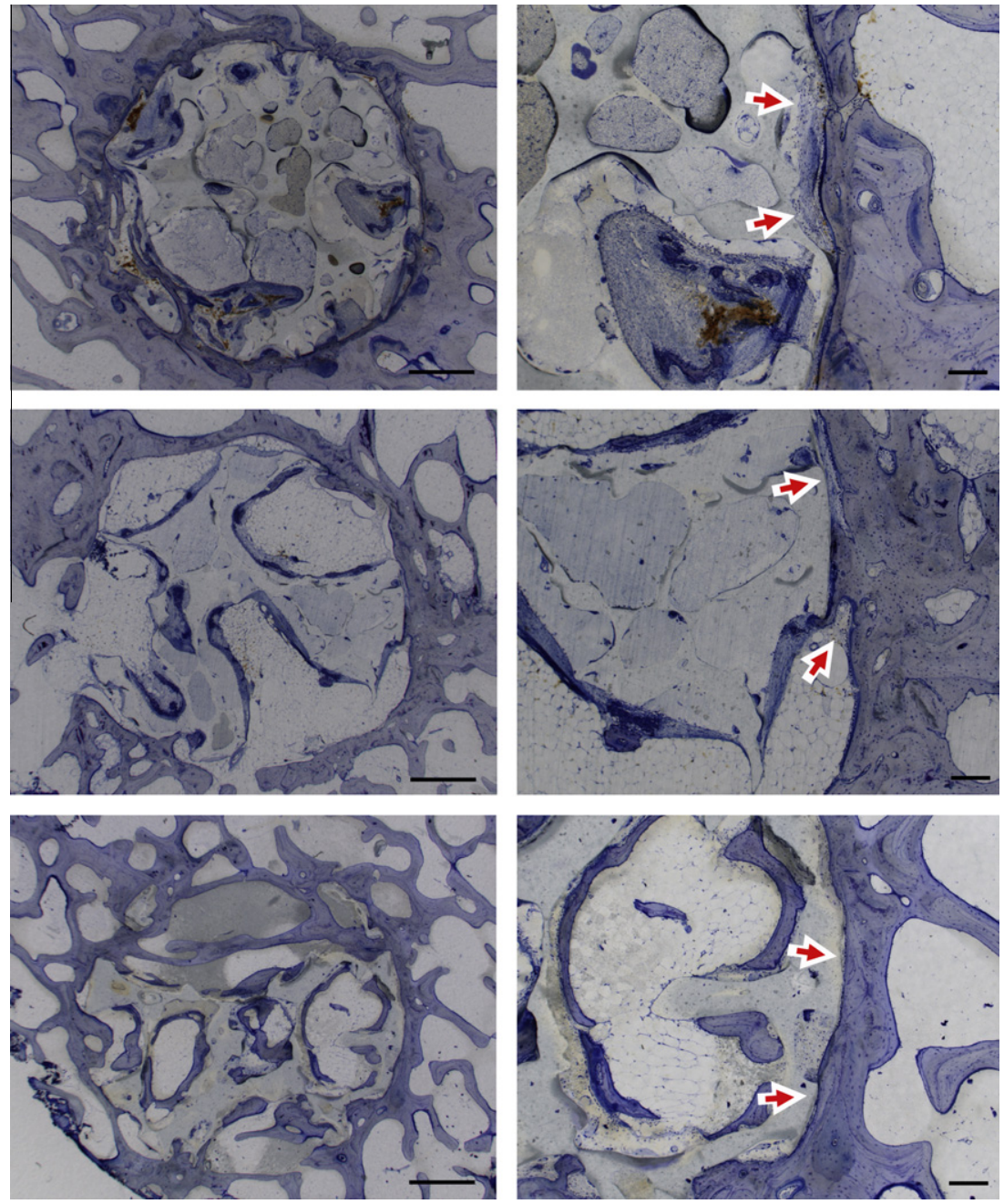

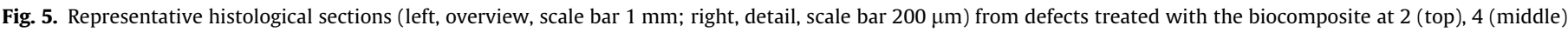

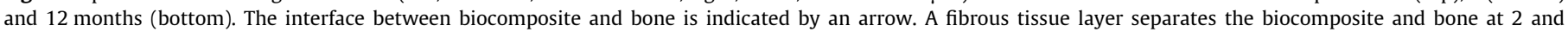
4 months, whereas at 12 months direct bone contact is observed.

A major finding of this study was incorporation of the biocomposite into bone after 12 months. Bone in-growth was observed in the biocomposite scaffold, including its central part. This is an important result as it has been mentioned that scaffolds often fail to support viable tissue in their interior, as shown in many in vitro studies [16]. Micro-CT scans presented a nice contrast between bone and polymer, thus allowing good visualization of bone ingrowth in biocomposite filled defects and ones left empty. Bone in-growth in those defects was slow in both cases and bone grew from the outside towards the inside of the defect. A similar trend was observed when the biocomposite was implanted in rat cranial defect and knee condyle models [17]. New bone formation and morphology differed between the empty and biocomposite groups: in the defects left empty new bone grew as a dense structure, forming a dense ring on the outer diameter of the defect, whereas a more trabecular like structure was obtained in the presence of the biocomposite at 12 months. The biocomposite served as a support for the formation of new bone: cells were guided by the scaffold structure to generate new bone. This structure was missing in the defect left empty, where cells grew layer by layer, forming a dense ring.

Porous PLA scaffolds have usually been combined with osteogenic factors such as cells $[17,18]$ or growth factors [19]. In the present study the bone in-growth observed at 12 months was exclusively due to the osteoconductive properties of the biocomposite. The presence of $\beta$-TCP particles in the biocomposite certainly plays a positive role in the observed bone in-growth.

The effect of the $\beta$-TCP particles has been specifically highlighted in a rabbit study, in which a clear correlation between the percentage of $\beta$-TCP particles incorporated in a PLA scaffold and bone healing was established [20]. A 40/60 wt.\% PLA/ $\beta$-TCP ratio showed the best results. Indeed, the positive effect of $\beta$-TCP on bone healing and on the absence of fibrous tissue was also demonstrated in the present study with the ChronOS ${ }^{\mathrm{TM}}$ scaffold. As early as 2 months good osteointegration of this scaffold was observed. It could then be advantageous to increase the amount of $\beta$-TCP in the developed biocomposite, which actually presents a 95/5 wt.\% PLA/ $\beta$-TCP ratio. However, due to processing of the biocomposite by super critical $\mathrm{CO}_{2}$ foaming, 5 wt.\% filler content was shown to be the upper limit to obtain a homogeneous and interconnected cellular architecture [10]. In addition, increasing the amount of $\beta$-TCP, would make the biocomposite more brittle and it would lose its ability to sustain any deformation.

It is interesting to note that if the study had been terminated after 4 months a negative conclusion would have been drawn, as fibrous tissue was still present at this time point. At 12 months no fibrous tissue could be found. The presence of fibrous tissue at early time points is the consequence of an inflammatory reac- 

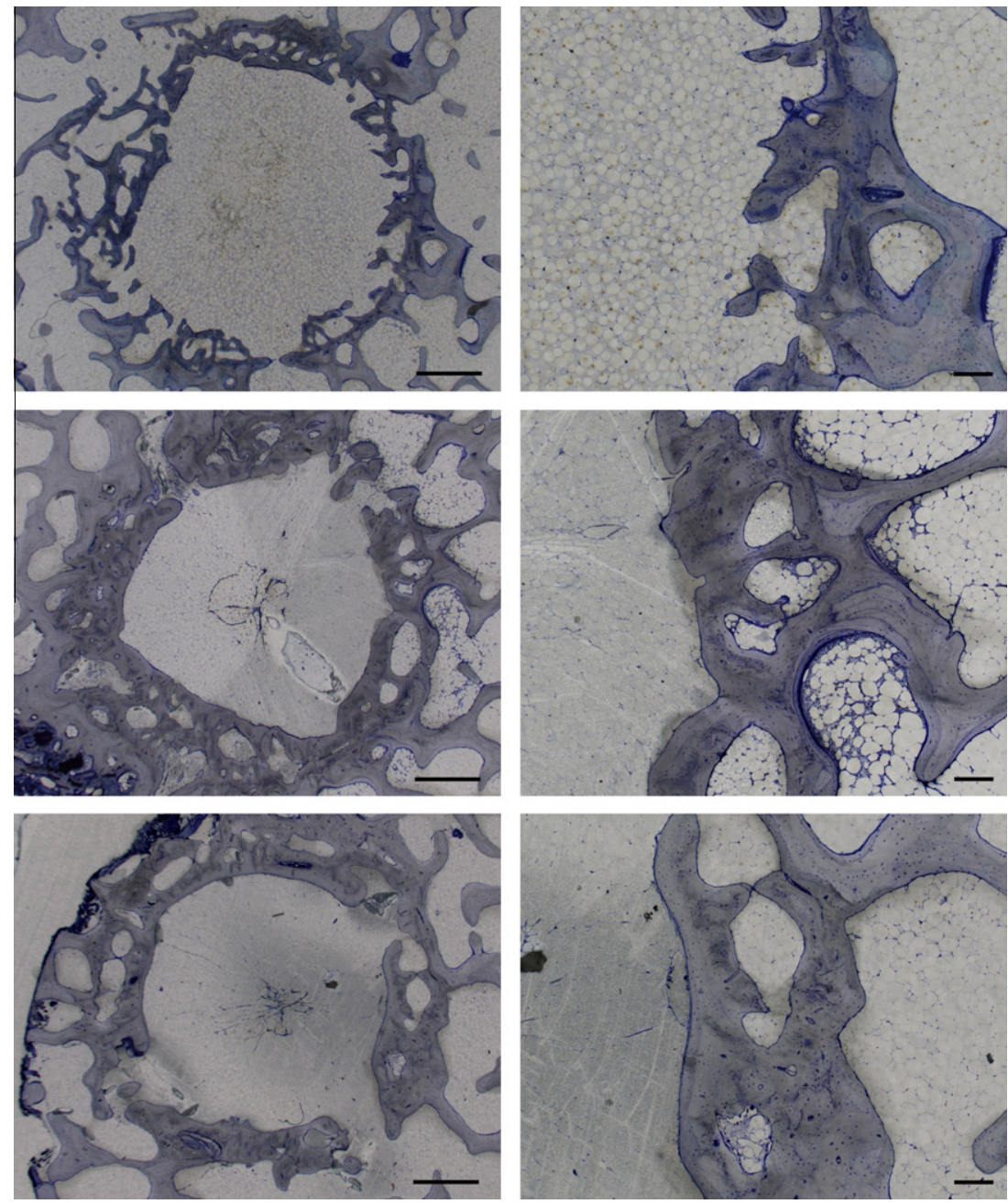

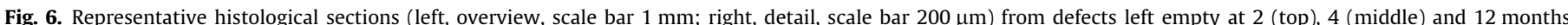

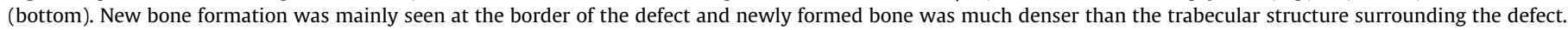

tion due to the presence of the scaffold. It has been reported that polymer scaffolds such as PLA may induce an inflammatory reaction, as this polymer releases lactic acid during its degradation [21]. It is the accumulation of this acid which becomes toxic [22]. The initial fibrous tissue formation observed in this study has been previously reported with PLA implants inserted into rabbits [20]. However, this fibrous tissue does not always disappear and may be present after more than 6 months $[20,23,24]$. The absence of fibrous tissue at 12 months in our study may be related to the presence of the $\beta$-TCP particles, as $\beta$-TCP has been shown to decrease the inflammatory reaction when composite PLA/ $\beta$ TCP scaffolds were implanted [20]. Indeed, in the present study most of the $\beta$-TCP particles were embedded in the PLA trabecula of the biocomposite scaffold, as was seen in a previous study [10]. These particles will be released and will positively influence biocomposite osteointegration only after degradation of the PLA has occurred. This process may explain why fibrous tissue was observed at 2 and 4 months but not at 12 months. To accelerate osteointegration of the biocomposite it could be advantageous to control the distribution of $\beta$-TCP particles in the PLA in order that some of them are on the surface of the PLA, not only embedded.

The degradation rate of the biocomposite was slow compared with the ChronOS ${ }^{\mathrm{TM}}$ scaffold. Even if the degradation rate of PLA, which is driven by a hydrolysis process, can be modulated by con- trolling its crystallinity [25] or morphology [26], to mention only two possibilities, the relatively slow degradation rate is common to many PLA materials. In this study the amount of biocomposite had decreased remarkably at 12 months compared with the earlier time points. A longer experiment would then be necessary to ascertain that no adverse effects would be found before complete degradation of the biocomposite. However, clinical studies using PLA materials demonstrate excellent incorporation, even in the slow degradation rate situation. For example, in a clinical application where PLA screws were used to fix a patellar tendon graft for anterior cruciate ligament replacement after 30 months the PLA screws were not completely degraded, while no inflammation was observed [27]. In a lumbar fusion application PLA cages were used in goats and followed for 48 months. At this time point no PLA was found in most of the animals treated and no inflammation was observed [28].

The degradation rate obviously should depend on the clinical applications targeted. In situations where the scaffold will play an important mechanical role the degradation rate should not be too fast to allow new bone formation to take over the mechanical load. The relatively slow rate of degradation of the biocomposite would then not be an inconvenience, as the scaffold would need to sustain the mechanical load in a situation such as that prevailing in total knee replacement. Slow degradation of the scaffold would 

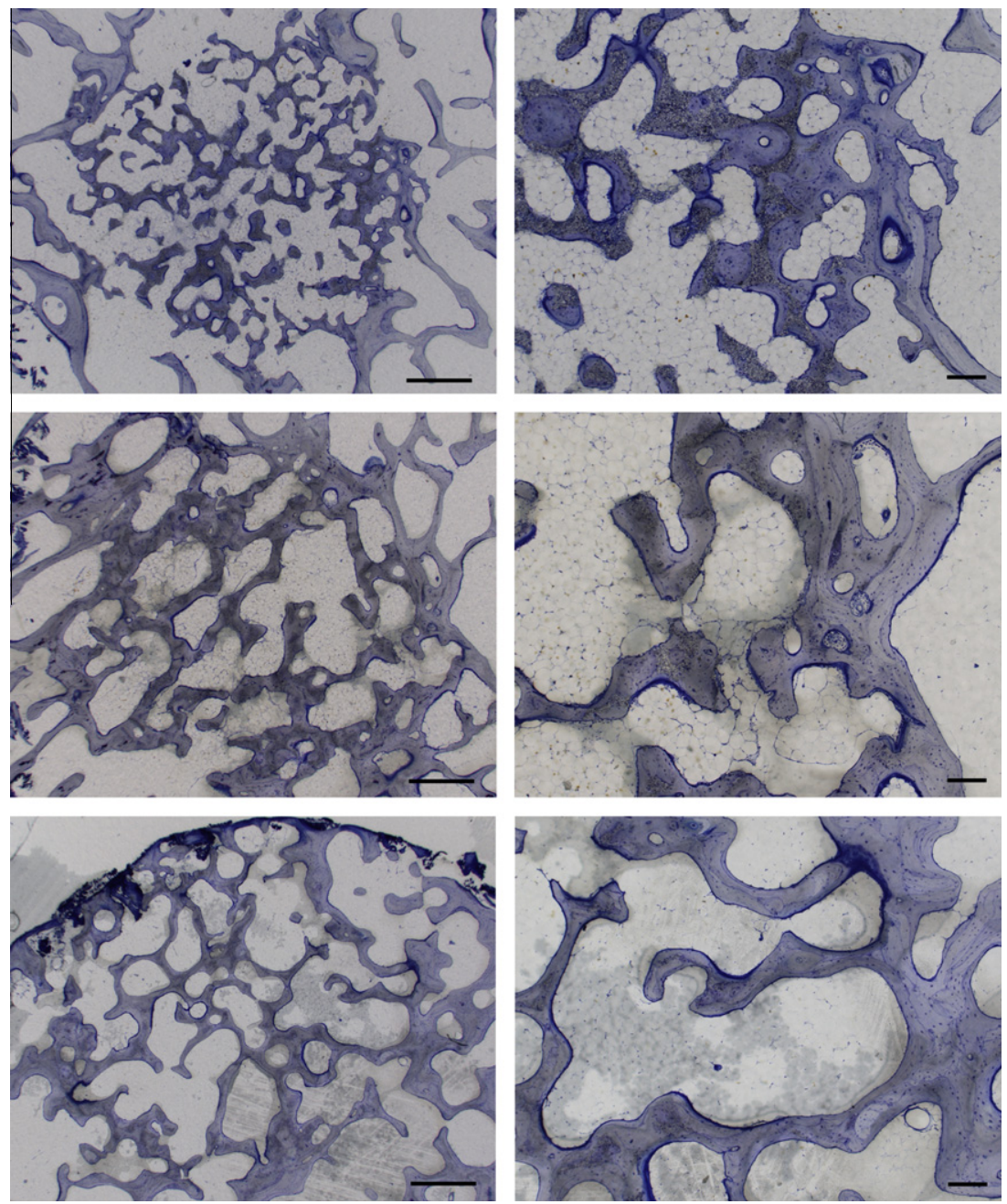

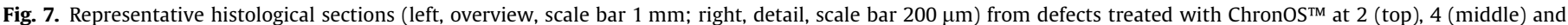
12 months (bottom).

then provide more certainty that the bone would have enough time to colonize the biocomposite, achieving the mechanical properties required to sustain the load [11].

The goal of this study was not to place calcium phosphate scaffolds such as ChronOSTM in competition with the developed biocomposite. Calcium phosphate scaffolds have been successful for several clinical applications [29] and were thus used in this study as a positive control for the in vivo model. As already mentioned, calcium phosphate scaffolds cannot sustain shock due to their brittle nature, rendering their use difficult in, for example, filling bone defects during total knee revision. For this particular application, based on a numerical study, we determined that the biocomposite could sustain a $1 \%$ deformation [11], due to its ductile behavior. This $1 \%$ deformation was recently demonstrated to increase bone formation during an in vivo study performed in rats [30]. Clearly, the biocomposite developed here is complementary to calcium phosphate scaffolds and could be used for clinical applications for which calcium phosphate scaffolds are not suitable. It should also be mentioned that the biocomposite scaffold allowed the use of screws, which is a complementary advantage compared with calcium phosphate scaffolds.

In conclusion, the developed biocomposite scaffold presented good results at 12 months in sheep, with no inflammation and slow but constant bone in-growth along the support, with the formation of new bone of trabecular structure. Due to its ductile behavior
[10], the biocomposite could find application in load bearing situations, such as in bone filling during revision of total knee arthroplasty.

\section{Acknowledgements}

This project was supported by the Inter-institutional Centre for Translational Biomechanics EPFL-CHUV-DAL and the Swiss National Science Foundation.

\section{Appendix A. Figures with essential colour discrimination}

Certain figures in this article, particularly Figures 2-7, are difficult to interpret in black and white. The full colour images can be found in the on-line version, at doi:10.1016/j.actbio.2010.03.028).

\section{References}

[1] Pioletti DP. Biomechanics in bone tissue engineering. Comp Meth Biomed Biomech Eng, in press. doi:10.1080/10255841003630660.

[2] Huff TW, Sculco TP. Management of bone loss in revision total knee arthroplasty. J Arthroplasty 2007;22(7 Suppl. 3):32-6.

[3] Oest ME, Dupont KM, Kong HJ, Mooney DJ, Guldberg RE. Quantitative assessment of scaffold and growth factor-mediated repair of critically sized bone defects. J Orthop Res 2007;25(7):941-50.

[4] Burg KJ, Porter S, Kellam JF. Biomaterial developments for bone tissue engineering. Biomaterials 2000;21(23):2347-59. 
[5] Middleton JC, Tipton AJ. Synthetic biodegradable polymers as orthopedic devices. Biomaterials 2000;21(23):2335-46.

[6] Zhang R, Ma PX. Poly(alpha-hydroxyl acids)/hydroxyapatite porous composites for bone-tissue engineering. I. Preparation and morphology. J Biomed Mater Res 1999;44(4):446-55.

[7] Causa F, Netti PA, Ambrosio L, Ciapetti G, Baldini N, Pagani S, et al. Polyepsilon-caprolactone/hydroxyapatite composites for bone regeneration: in vitro characterization and human osteoblast response. J Biomed Mater Res A 2006;76(1):151-62.

[8] Kim SS, Ahn KM, Park MS, Lee JH, Choi CY, Kim BS. A poly(lactide-co-glycolide)/ hydroxyapatite composite scaffold with enhanced osteoconductivity. J Biomed Mater Res A 2007;80(1):206-15.

[9] Mathieu LM, Montjovent MO, Bourban PE, Pioletti DP, Manson JA. Bioresorbable composites prepared by supercritical fluid foaming. J Biomed Mater Res A 2005;75(1):89-97.

[10] Mathieu LM, Mueller TL, Bourban PE, Pioletti DP, Muller R, Manson JA. Architecture and properties of anisotropic polymer composite scaffolds for bone tissue engineering. Biomaterials 2006;27(6):905-16.

[11] Terrier A, Sedighi-Gilani M, Roshan Ghias A, Aschwanden L, Pioletti DP. Biomechanical evaluation of porous biodegradable scaffolds for revision knee arthroplasty. Comput Methods Biomech Biomed Eng 2009;12(3):333-9.

[12] Montjovent MO, Mathieu L, Schmoekel H, Mark S, Bourban PE, Zambelli PY, et al. Repair of critical size defects in the rat cranium using ceramic-reinforced PLA scaffolds obtained by supercritical gas foaming. J Biomed Mater Res A 2007;83(1):41-51.

[13] Nuss KM, Auer JA, Boos A, von Rechenberg B. An animal model in sheep for biocompatibility testing of biomaterials in cancellous bones. BMC Musculoskelet Disord 2006;7:67.

[14] Bohner M. Calcium phosphate emulsions: possible applications. Key Eng Mater 2001;192-195:765-8.

[15] Zeiter S, van der Pol U, van der Pol B, Leitner M, Tami A, Pioletti DP, et al. A large animal model for standardized evaluation of bone substitutes in cancellous bone. eCM, submitted for publication.

[16] Karande TS, Ong JL, Agrawal CM. Diffusion in musculoskeletal tissue engineering scaffolds: design issues related to porosity, permeability, architecture, and nutrient mixing. Ann Biomed Eng 2004;32(12):1728-43.

[17] Montjovent MO, Mark S, Mathieu L, Scaletta C, Scherberich A, Delabarde C, et al. Human fetal bone cells associated with ceramic reinforced PLA scaffolds for tissue engineering. Bone 2008;42(3):554-64.
[18] Jung Y, Kim SS, Kim YH, Kim SH, Kim BS, Kim S, et al. A poly(lactic acid)/ calcium metaphosphate composite for bone tissue engineering. Biomaterials 2005;26(32):6314-22

[19] Yang XB, Whitaker MJ, Sebald W, Clarke N, Howdle SM, Shakesheff KM, et al. Human osteoprogenitor bone formation using encapsulated bone morphogenetic protein 2 in porous polymer scaffolds. Tissue Eng 2004;10(7/ 8):1037-45.

[20] Aunoble S, Clement D, Frayssinet P, Harmand MF, Le Huec JC. Biological performance of a new beta-TCP/PLLA composite material for applications in spine surgery: In vitro and in vivo studies. J Biomed Mater Res A 2006;78(2):416-22.

[21] Pihlajamaki H, Bostman O, Tynninen O, Laitinen O. Long-term tissue response to bioabsorbable poly-L-lactide and metallic screws: an experimental study. Bone 2006;39(4):932-7.

[22] von Recum HA, Cleek RL, Eskin SG, Mikos AG. Degradation of polydispersed poly(L-lactic acid) to modulate lactic acid release. Biomaterials 1995;16(6):441-7.

[23] van der Elst M, Klein CP, de Blieck-Hogervorst JM, Patka P, Haarman HJ. Bone tissue response to biodegradable polymers used for intra medullary fracture fixation: a long-term in vivo study in sheep femora. Biomaterials 1999;20(2):121-8

[24] Merolli A, Gabbi C, Cacchioli A, Ragionieri L, Caruso L, Giannotta L, et al. Bone response to polymers based on poly-lactic acid and having different degradation times. J Mater Sci Mater Med 2001;12(9):775-8.

[25] Pistner H, Bendix DR, Muhling J, Reuther JF. Poly(L-lactide): a long-term degradation study in vivo. Part III. Analytical characterization. Biomaterials $1993 ; 14(4): 291-8$

[26] Grizzi I, Garreau H, Li S, Vert M. Hydrolytic degradation of devices based on poly(DL-lactic acid) size-dependence. Biomaterials 1995;16(4):305-11.

[27] Martinek V, Seil R, Lattermann C, Watkins SC, Fu FH. The fate of the poly-Llactic acid interference screw after anterior cruciate ligament reconstruction. Arthroscopy 2001;17(1):73-6.

[28] van Dijk M, van Diest PJ, Smit TH, Berkhof H, Burger EH, Wuisman PI. Four-year follow-up of poly-L-lactic acid cages for lumbar interbody fusion in goats. J Long Term Eff Med Implants 2005;15(2):125-38.

[29] Bohner M. Calcium orthophosphates in medicine: from ceramics to calcium phosphate cements. Injury 2000;31(Suppl. 4):37-47.

[30] Roshan-Ghias A, Terrier A, Bourban PE, Pioletti DP. In vivo cyclic loading as a potent stimulatory signal for bone formation inside tissue engineering scaffold. Eur Cell Mater 2010;19:41-9. 